\title{
Identification and Quantification of Sucrose Esters in Various Turkish Tobaccos*
}

\author{
by \\ M. Ashraf-Khorassani ${ }^{1}$, N. Nazem ${ }^{1}$, L.T. Taylor ${ }^{1}$, and W. M. Coleman III ${ }^{2}$ \\ ${ }^{1}$ Department of Chemistry, Virginia Tech, Blacksburg, VA 24061-0212, USA \\ ${ }^{2}$ R. J. Reynolds Tobacco Company, Winston Salem, NC 27106-1487, USA
}

\section{SUMMARY}

Gas chromatography-mass spectrometry (GC-MS) and reversed-phase liquid chromatography-mass spectrometry (LC-MS) were used to compare and quantify sucrose esters (SE) in five different tobaccos. The concentration of SE varied from 340 to $950 \mu \mathrm{g} / \mathrm{g}$. In order to quantify the $\mathrm{SE}$ in each tobacco, the trimethylsilane (TMS) derivative of each sample was analyzed via GC-MS. It appeared that in the five tobaccos, the intensities of the five chosen SE-derived molecular masses increased in the order $m / z, 622<636<$ $678<650<664$ for samples $1-3$, but for samples 4 and 5 , the $m / z 678$ and 650 were reversed. In order to qualitatively characterize the various SE chromatographic fractions LCMS was used. It was determined that the lowest parent SE $\mathrm{m} / \mathrm{z}$ in which acetyl was attached to glucose was detected at $\mathrm{m} / \mathrm{z} 566$ (10 carbons), and the highest $\mathrm{m} / \mathrm{z}$ was found at 692 (19 carbons). Some $\mathrm{m} / z$ values showed more than one peak which indicated the presence of isomers. All samples showed the presence of at least five different SE peaks wherein acetyl was attached to fructose (i.e. $\mathrm{m} / \mathrm{z} 205$ ). Also, acyl unsaturation was observed in selected fractions. [Beitr. Tabakforsch. Int. 21 (2005) 441-450]

\section{ZUSAMMENFASSUNG}

In fünf verschiedenen Tabaken wurden Saccharoseester (SE) mittels Gaschromatographie-Massenspektrometrie (GC-MS) und Reversed Phase Flüssigkeitschromatographie-Massenspektrometrie (LC-MS) miteinander verglichen und quantifiziert. Die SE-Konzentrationen lagen bei 340 bis $950 \mu \mathrm{g} / \mathrm{g}$ Tabak. Um die SE-Mengen in jedem Tabak quantitativ zu bestimmen, wurden die Trimethylsilyl (TMS)-Derivate mittels GC-MS analysiert. Hierbei zeigte sich bei den fünf Tabaken, dass die Intensitäten der fünf ausgewählten Mole- kularmassen der SE-Derivate bei den Proben 1 bis 3 in der Reihenfolge $m / z, 622<636<678<650<664$ zunahmen, bei den Proben 4 und 5 die Intensitäten für $\mathrm{m} / z 678$ und 650 jedoch umgekehrt waren. Die qualitative Charakterisierung der verschiedenen, zuvor mittels semi-präparativer HPLC gewonnenen Fraktionen der SE erfolgte mittels LC-MS. Es wurde festgestellt, dass der niedrigste $\mathrm{m} / \mathrm{z}$-Wert für die Ausgangs-SE, bei dem Acetyl an Glukose gebunden war, bei 566 (10 Kohlenstoffatome), der höchste bei 692 (19 Kohlenstoffatome) lag. Einige $m / z$-Werte zeigten mehr als einen Peak, was auf das Vorhandensein von Isomeren hindeutete. Alle Proben zeigten mindestens fünf verschiedene SE-Peaks, wobei Acetyl an Fruktose gebunden war (und zwar $m / z$ 205). Des weiteren wurde in bestimmten Fraktionen ein geringerer Sättigungsgrad mit Acyl-Gruppen beobachtet. [Beitr. Tabakforsch. Int. 21 (2005) 441-450]

\section{RESUME}

Des esters de saccharose (SE) de cinq variétés de tabacs ont été comparés et quantifiés par chromatographie en phase gazeuse-spectrométrie de masse (GC-MS) et par chromatographie liquide en phase inverse-spectrométrie de masse (LC-MS). Les teneurs en SE ont varié de 340 à $950 \mu / g$. Pour quantifier la teneur en SE dans chaque variété, le dérivé du triméthylsilane (TMS) de chaque échantillon a été analysé par GC-MS. Dans les cinq variétés de tabac, les intensités des cinq masses moléculaires choisies des dérivés de SE augmentent dans l'ordre de $m / z 622<636<678<$ $650<664$ chez les échantillons $1-3$, mais chez les échantillons 4 et 5 , les intensités de $m / z 678$ et 650 sont inversées. Les diverses fractions chromatographiques des SE ont été caractérisées qualitativement par LC-MS. Il a été déterminé que la valeur $m / z$ la plus basse du SE d'origine, où les groupes acétyle ont été attachés au glucose, a été détectée 
à 566 (10 carbones), la valeur $m / z$ la plus élevée à 692 (19 carbones). Quelques valeurs $m / z$ montrent plus d'un pic ce qui indique la présence d'isomères. Tous les échantillons démontrent la présence d'au moins cinq différents pics, où l'acétyle a été attaché au fructose (à savoir $m / z$ 205). De plus, dans des fractions sélectionnées un faible taux de saturation des groupes d'acétyle a été observé. [Beitr. Tabakforsch. Int. 21 (2005) 441-450]

\section{INTRODUCTION}

A major group of tobacco surface chemicals is the sucrose esters (SE). These compounds are found in glandular trichome exudates of many plants of the family Solonaceae (1). Potato species may also contain SE (2). The first report of SE came in 1970 with the isolation, structure elucidation, and synthesis of 6-O-acetyl-2,3,4-tri- $O-[(+)-3$-methylvaleryl]- $\beta$-D-glucopyranose (i.e. a glucose tetraester) (3). This and the more predominant sucrose tetraesters of lower carboxylic acids are now considered to be some of the most important aroma precursors responsible for Oriental flavor (4). In Nicotiana, SE are well characterized and are grouped into at least eight types of acetylated or non-acetylated 2,3,4tri- $O$-acyl- $\alpha$-D-glucopyranoside- $\alpha$-D-fructofuranosides where the acyl groups are $C_{3}$ to $C_{8}$ straight or branched aliphatic acids (5). Only in one published case has an unsaturated acyl constitutent with one double bond been shown (6). While all known Nicotiana SE contain three acyl groups on the glucose moiety, the nature of groups occurring at specific positions (e.g. 2, 3, or 4) can apparently vary, as can the nature of mixtures of acyl groups found in an SE type. Also, the number and position of acetyl groups occurring in SE may vary (e.g. C-6 of glucose or C-2/C-3 of fructose. Thus, the number of distinct $\mathrm{SE}$ structures produced by members of the Nicotiana is tremendous (7).

Until recently SE and their acyl constituents have generally been characterized using gas chromatography (GC) or gas chromatography-mass spectrometry (GC-MS) of either sucrose methyl/butyl esters or sucrose trimethylsilyl ether derivatives $(8,9)$. Inferences concerning acyl substitution patterns on the sucrose ester from data obtained by acid hydrolysis of the ester and re-derivatization of the released carboxylic acid have also been reported. In these studies various methods have been used to extract and isolate SE from green tobacco leaf.

SEVERSON et al. (10,11) developed a gel filtration-partition chromatography method using Sephadex LH-20 to isolate individual groups of SE. In this method, green tobacco leaf was washed with $\mathrm{CH}_{2} \mathrm{Cl}_{2}$ followed by a series of evaporation and extraction steps using different solvents. The final extract in $\mathrm{CHCl}_{3}$ was fractionated first on a $\mathrm{LH}-20$ column with inner diameter of $2.54 \mathrm{~cm}$ and bed length of $58 \mathrm{~cm}$. The SE gel fractions were evaporated to dryness and redissolved in $3 \mathrm{~mL}$ of $\mathrm{CHCl}_{3}$. This fraction was separated once again on a $1.37 \mathrm{~cm}$ i.d. column (bed length $110 \mathrm{~cm}$ ). Elution with $\mathrm{CHCl}_{3}$ produced another fraction. This fraction was then used with another gel filtration column to isolate each SE. SEVERSON et al. were able to isolate 6 groupings of ester isomers, differing by $14 \mathrm{amu}$. Later DANEHOWER (12) used a silica gel solid phase cartridge to clean the
$\mathrm{CH}_{2} \mathrm{Cl}_{2}$ extract of the leaf surface. First, the extract was loaded into the solid phase extraction (SPE) cartridge and washed with $\mathrm{CH}_{2} \mathrm{Cl}_{2}$. It was demonstrated that most of the polar compounds including $\mathrm{SE}$ were retained on the column and were not washed out with $\mathrm{CH}_{2} \mathrm{Cl}_{2}$. Next, methanol was used to quantitatively remove the $\mathrm{SE}$ from the silica column. It was shown by GC that $50 \%$ of the total material from the leaf surface was cleaned up using this technique, while $99 \%$ of the SE was retained on the SPE column. In an even later study by KANDRA et al. (13), $\mathrm{CH}_{3} \mathrm{CN}$ was used as an extraction solvent in order to wash the green leaf surface. Unfortunately, they did not use $\mathrm{CH}_{2} \mathrm{Cl}_{2}$ in order to avoid extraction of cuticular hydrocarbons which interferes with the SE separation. After $\mathrm{CH}_{3} \mathrm{CN}$ extraction, the SEenriched sample was extracted with $\mathrm{CHCl}_{3}: \mathrm{H}_{2} \mathrm{O}(2: 1, \mathrm{v} / \mathrm{v})$ to remove $\mathrm{H}_{2} \mathrm{O}$-soluble materials. The $\mathrm{CHCl}_{3}$ phase was dried and later was separated by high performance liquid chromatography (HPLC) using a Cyano column. The workers were able to isolate four fractions from the HPLC separation with the last fraction being SE.

More recently (14) this enriched tobacco fraction of SE from semi-preparative normal phase LC of the methylene chloride extract was chosen for characterization via HPLCMS. Several types of SE were observed in the single tobacco that was studied that differed primarily in placement of the acyl functionality on either the glucose or the fructose fragment. In addition to acetyl, the other three observed acyl substitution patterns were governed by the presence of butyl, pentyl, and hexyl alkyl substituents. Within each type of SE, there were observed several homologs differing by a methylene moiety. Within each homolog, a number of isomeric components were found. The presence of unsaturation in one of the acyl alkyl substituents gave rise to another homologous series wherein isomers of the same mass were discovered.

Supercritical $\mathrm{CO}_{2}$ at various pressures and temperatures has been used to effect the fractionation of tetra-acyl sucrose esters (SE) from dried, ground Turkish tobacco without any further pretreatment of the matrix (15). It was determined that SE can not be extracted using low density $\mathrm{CO}_{2}(150 \mathrm{~atm}$, $60{ }^{\circ} \mathrm{C}, 0.62 \mathrm{gm} / \mathrm{mL}$ or $\left.200 \mathrm{~atm}, 100{ }^{\circ} \mathrm{C}, 0.49 \mathrm{gm} / \mathrm{mL}\right)$, whereas other analytes which strongly interfere with the conventional solvent extraction of SE can be easily removed under the same conditions. At the higher temperature $\left(100{ }^{\circ} \mathrm{C}\right)$, these same analytes that interfere with the conventional solvent extraction of SE are even more readily removed; while the very poor extractability of SE is not affected. It was demonstrated, however, that SE can be readily removed from the pre-extracted tobacco with supercritical $\mathrm{CO}_{2}$ if the density is greater than (or equal to) $0.73 \mathrm{gm} / \mathrm{mL}$. The supercritical fluid extraction method was compared with other previous extraction methods that employ conventional solvents.

SE are most abundant in Turkish type tobaccos but high levels can be found in certain flue-cured, primitive, and pale yellow type tobaccos. They are less common in burley and Maryland types (16). SE are apparently stable past harvest. When pyrolyzed, acyl groups are released as volatile acids and these contribute to flavor and aroma. Whereas, totally esterified sucrose and glucose esters such as glucose pentaisovalerate and sucrose octaesters do not easily release their acid moieties on thermolysis. Turkish type tobaccos, for example, are thought to be enriched in 
the 3-methylvaleryl acyl group that is released on pyrolysis to give 3-methylvaleric acid which is the principle "Turkish note" of their smoke (17). In the work reported here, we have compared via HPLC-MS five unique Turkish tobacco samples concerning the molecular characterization and quantification of $\mathrm{SE}$ in classical liquid phase tobacco extracts employing the separation protocol outlined by SEVERSON et al. (11).

\section{EXPERIMENTAL}

All air-dried, ground Turkish tobacco samples were obtained from R.J. Reynolds Tobacco Co. (Winston-Salem, NC). Solvents were EM Science (Gibbstown, NJ) HPLC grade and were used as received. Dimethylformamide (DMF), potassium chloride, and sodium sulfate were obtained from Sigma-Aldrich (Milwaukee, WI). N,Obis(trimethylsilyl)trifluoroacetamide (BSTFA) (Alltech Associate, Deerfield, IL) was silylation grade.

For each extraction, $2 \mathrm{~g}$ of tobacco was transferred into a $100 \mathrm{~mL}$ bottle fitted with a Teflon coated cap. Then, $20 \mathrm{~mL}$ of $\mathrm{CH}_{2} \mathrm{Cl}_{2}$ was added to the bottle and the sample was manually shaken for 3-5 min. The solution was filtered using a type 1 filter paper. The residual tobacco and filter paper were transferred into the bottle where tobacco was reextracted using an additional $20 \mathrm{~mL}$ of fresh $\mathrm{CH}_{2} \mathrm{Cl}_{2}$. The combined $\mathrm{CH}_{2} \mathrm{Cl}_{2}$ extracts were evaporated to dryness using a nitrogen stream. The residue was then partitioned between $20 \mathrm{~mL}$ each of hexane and $80 \% \mathrm{MeOH}-\mathrm{H}_{2} \mathrm{O}$. The $\mathrm{MeOH}-\mathrm{H}_{2} \mathrm{O}$ solution was re-extracted a second time using an additional $20 \mathrm{~mL}$ of hexane. Next, $10 \mathrm{~mL}$ of saturated $\mathrm{KCl}$ solution was added to the $\mathrm{MeOH}-\mathrm{H}_{2} \mathrm{O}$ solution followed by $15 \mathrm{~mL}$ of $\mathrm{CHCl}_{3}$. The $\mathrm{CHCl}_{3}$ solubles were removed and the aqueous phase was extracted with another $15 \mathrm{~mL}$ of $\mathrm{CHCl}_{3}$. The combined $\mathrm{CHCl}_{3}$ fractions were then washed with $\mathrm{H}_{2} \mathrm{O}$ and filtered through anhydrous $\mathrm{Na}_{2} \mathrm{SO}_{4}$. After the solvent was removed, the extract was quantitatively re-dissolved in $10 \mathrm{~mL}$ of $\mathrm{CHCl}_{3}$. The extract at this point was derivatized and analyzed via GC-MS, vide infra. In order to obtain cleaner fractions of SE for liquid chromatography-mass spectrometry (LC-MS) analysis, semi-preparative HPLC was applied to each of the underivatized extracts that had been re-constituted in $\mathrm{CHCl}_{3}$. All normal phase semi-preparative HPLC separations were conducted using an Agilent series 1050 HPLC equipped with a multi-wavelength ultraviolet (UV) detector and 3396 integrator. All normal phase semi-preparative HPLC separations were obtained using an analytical Supelco (Bellefonte, PA) Cyano column $(250 \times 4.6 \mathrm{~mm}$ and $250 \times$ $\left.10 \mathrm{~mm}, 5 \mu \mathrm{m} d_{\mathrm{p}}\right)$. Separation was achieved and fractions were collected via isocratic elution using isooctane:ethanol $(85: 15 \%)$ at room temperature flowing $0.8 \mathrm{~mL} / \mathrm{min}$. UV detection was set at $214 \mathrm{~nm}$. The isolated and purer SE were further separated, detected, and identified via reversed-phase HPLC-MS as will be described later.

\section{GC-MS analysis}

After completion of the preliminary extraction method, $0.5 \mathrm{~mL}$ of $\mathrm{CHCl}_{3}$ solution from each extract was quantitatively transferred into a GC vial for derivatization. The solvent was evaporated to dryness using $\mathrm{N}_{2}$ at room temperature. A $500 \mu \mathrm{L}$ portion of 1:1 BSTFA:DMF was added to each vial for the purpose of forming silyl ethers of the unacylated hydroxyl groups on each SE molecule. Each vial was purged with $\mathrm{N}_{2}$ and capped with a Teflon-lined cap and heated at $70{ }^{\circ} \mathrm{C}$ for $30 \mathrm{~min}$. After cooling, the sample was placed inside the 7673 Agilent autosampler for GC analysis. For quantitative analysis, SE were analyzed as their trimethylsilyl ether derivative using an Agilent 5890 gas chromatograph (Wilmington, DE) equipped with a 5972 Mass Selective Detector (MSD). GC separations were performed on a DB-5 MS capillary column $(15 \mathrm{~m} \times 0.25$ $\mathrm{mm}$ i.d., $0.25 \mu \mathrm{m} d_{\mathrm{f}}$ ). All GC runs were carried out using the following temperature programming: Initial temperature $80{ }^{\circ} \mathrm{C}$, hold for $2 \mathrm{~min}$, ramp to $140{ }^{\circ} \mathrm{C}$ at rate of $10{ }^{\circ} \mathrm{C} / \mathrm{min}$ and then ramp to $290{ }^{\circ} \mathrm{C}$ at rate of $4{ }^{\circ} \mathrm{C} / \mathrm{min}$, hold at $290{ }^{\circ} \mathrm{C}$ for $10 \mathrm{~min}$.

\section{HPLC-MS analysis}

Reversed-phase LC separations were obtained with an Eclipse $\mathrm{C}_{18}(100 \times 2.0 \mathrm{~mm}, 3.0 \mu \mathrm{m})$ column from Agilent (Wilmington, DE). All reversed-phase HPLC separations were obtained on underivatized SE using an Agilent (Wilmington, DE) HPLC 1100 series equipped with a diode array detector, column heater, and Thermo Survey (San Jose, CA) autosampler. In each analysis, $10 \mu \mathrm{L}$ of a methanol solution of the cleaned-up SE extract was injected onto the column via the autosampler. Mobile phase A consisted of $1 \%$ aqueous formic acid, while mobile phase $\mathrm{B}$ contained $1 \%(\mathrm{v} / \mathrm{v})$ formic acid in acetonitrile. The mobile phase was delivered to the HPLC column at a flow rate of $0.2 \mathrm{~mL} / \mathrm{min}$ and the gradient mobile phase elution program was as follows: time $0-3 \mathrm{~min}, 100 \% \mathrm{~A}$; time 45 min, 100\% B; time $55 \mathrm{~min}, 100 \% \mathrm{~B}$; time $60 \mathrm{~min}, 100 \% \mathrm{~A}$; 5 min post run.

For MS analysis the HPLC column effluent was pumped directly (without any split) into the Thermo Instrument TSQ triple quadrupole mass spectrometer (Thermo Finnigan, San Jose, CA) equipped with an ESI source. The instrument was calibrated with a solution of polytyrosin according to the manufacture's recommendation. Tuning parameters were obtained via trial and error in order to achieve reasonable MS sensitivity and analyte identification information. MS parameters for separation and detection of the SE are listed below:

Spray voltage:

Sheath gas pressure: $\quad 49 \mathrm{psi}$

Auxiliary gas pressure: $13 \mathrm{psi}$

Capillary temperature: $\quad 300{ }^{\circ} \mathrm{C}$

\section{RESULTS AND DISCUSSION}

In the first part of this research, five different tobaccos were extracted using a method described in the Experimental section. Then, SE in each tobacco extract was quantified via GC-MS after derivatization. In this part of the study, $50 \mu \mathrm{L}$ of pyrene at a concentration of $10 \mathrm{ng} / \mu \mathrm{L}$ was used as an internal standard for each extract. This compound was chosen as the internal standard because it did not interfere with the chromatographic elution of the compounds of 

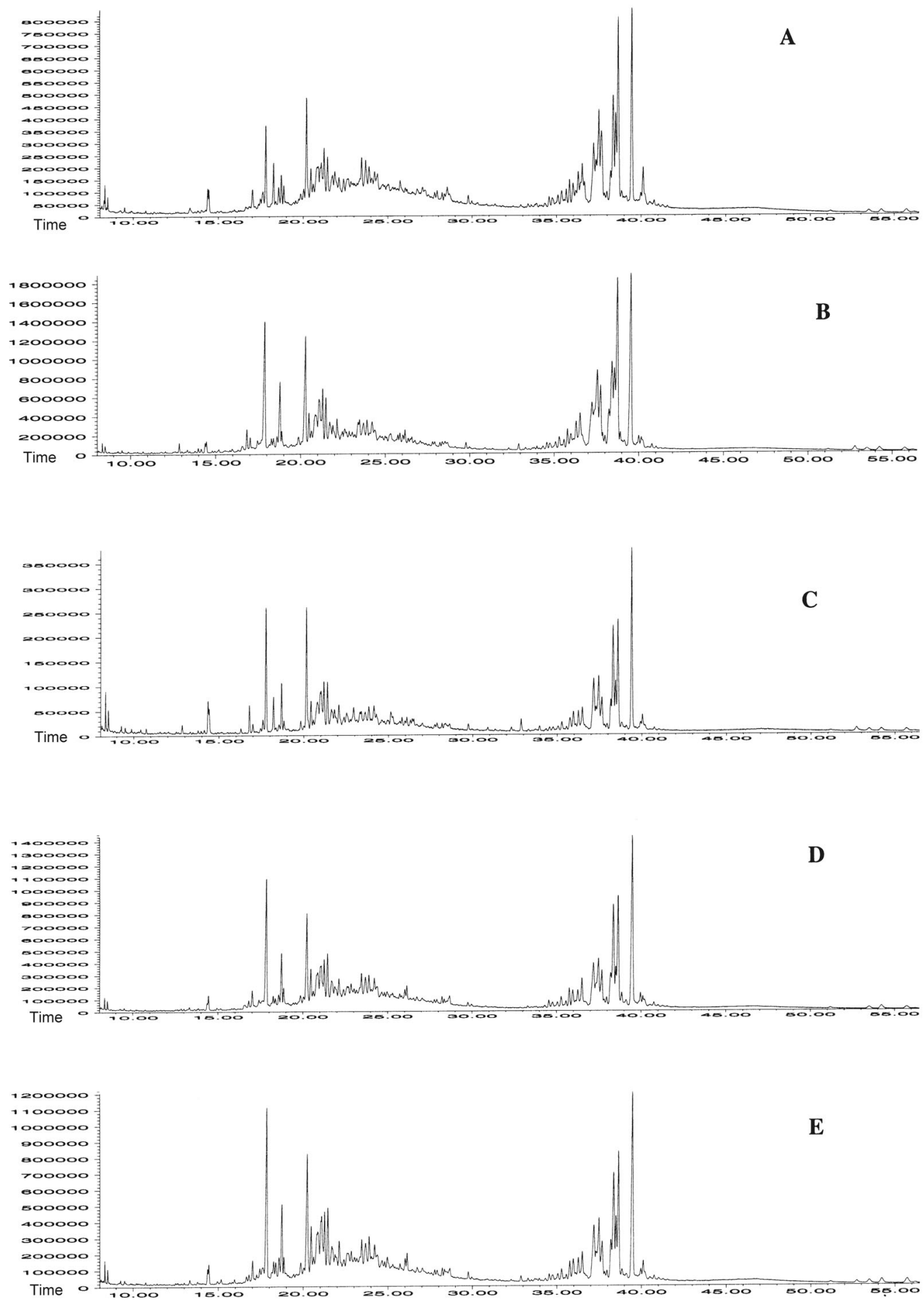

Figure 1. TIC for GC-MS of five tobacco extracts of SE after derivatization with BSTFA-DMF

interest. Figure 1 shows the GC-MS of each extract after derivatization using 1:1 BSTFA:DMF. Chromatographic traces for all extracts were similar. However, quantitative results for each extract were different. In order to compare the concentration of SE in each tobacco extract, five SE-derived ions each related to a specific SE were spectrometrically extracted (443, 457, 471, 485, and 499 amu). In other words, these ions were fragments of five variously substituted SE that had been reacted to yield trimethylsilyl ethers. Table 1 shows the concentration of each specific ion in the five different tobaccos. Regardless of the extracted ion, sample 2 always clearly had the highest concentration. The concentration of each SE thereafter varied. Sample 3 generally exhibited low (if not the lowest) concentrations of SE. In terms of summed concentration, sample 3 was definitely the lowest. The five chosen SE-derived molecular masses increased in the order $622<636<678<650<664$ for samples $1-3$, but for samples 4-5, 678 and 650 were reversed.

In the second part of this study, SE in five different Turkish tobacco extracts were more fully identified via LC-MS 
Table 1. GC-MS summed mass recovery of SE from Turkish tobacco as a function of SE molecular mass using a related extracted ion for quantification and pyrene as an internal standard

\begin{tabular}{l|c|c|c|c|c|c}
\hline Molecular mass of specific SE & $\begin{array}{c}\text { Related extracted } \\
\text { ion }\end{array}$ & $\begin{array}{c}\text { Sample 1 } \\
(\mu \mathrm{g} / \mathrm{g})\end{array}$ & $\begin{array}{c}\text { Sample 2 } \\
(\mu \mathrm{g} / \mathrm{g})\end{array}$ & $\begin{array}{c}\text { Sample 3 } \\
(\mu \mathrm{g} / \mathrm{g})\end{array}$ & $\begin{array}{c}\text { Sample 4 } \\
(\mu \mathrm{g} / \mathrm{g})\end{array}$ & $\begin{array}{c}\text { Sample 5 } \\
(\mu \mathrm{g} / \mathrm{g})\end{array}$ \\
\hline 622 & 443 & 11.1 & 21.9 & 4.7 & 4.9 & 4.8 \\
636 & 457 & 60.2 & 95.6 & 33.5 & 45.1 & 37.8 \\
650 & 471 & 134.4 & 247.6 & 89.0 & 122.5 & 100.0 \\
664 & 485 & 176.9 & 395.9 & 137.4 & 209.2 & 170.8 \\
678 & 499 & 76.2 & 190.5 & 77.6 & 137.1 & 105.4 \\
Total concentration & & 458.8 & 951.5 & 342.2 & 518.8 & 418.8 \\
\hline
\end{tabular}
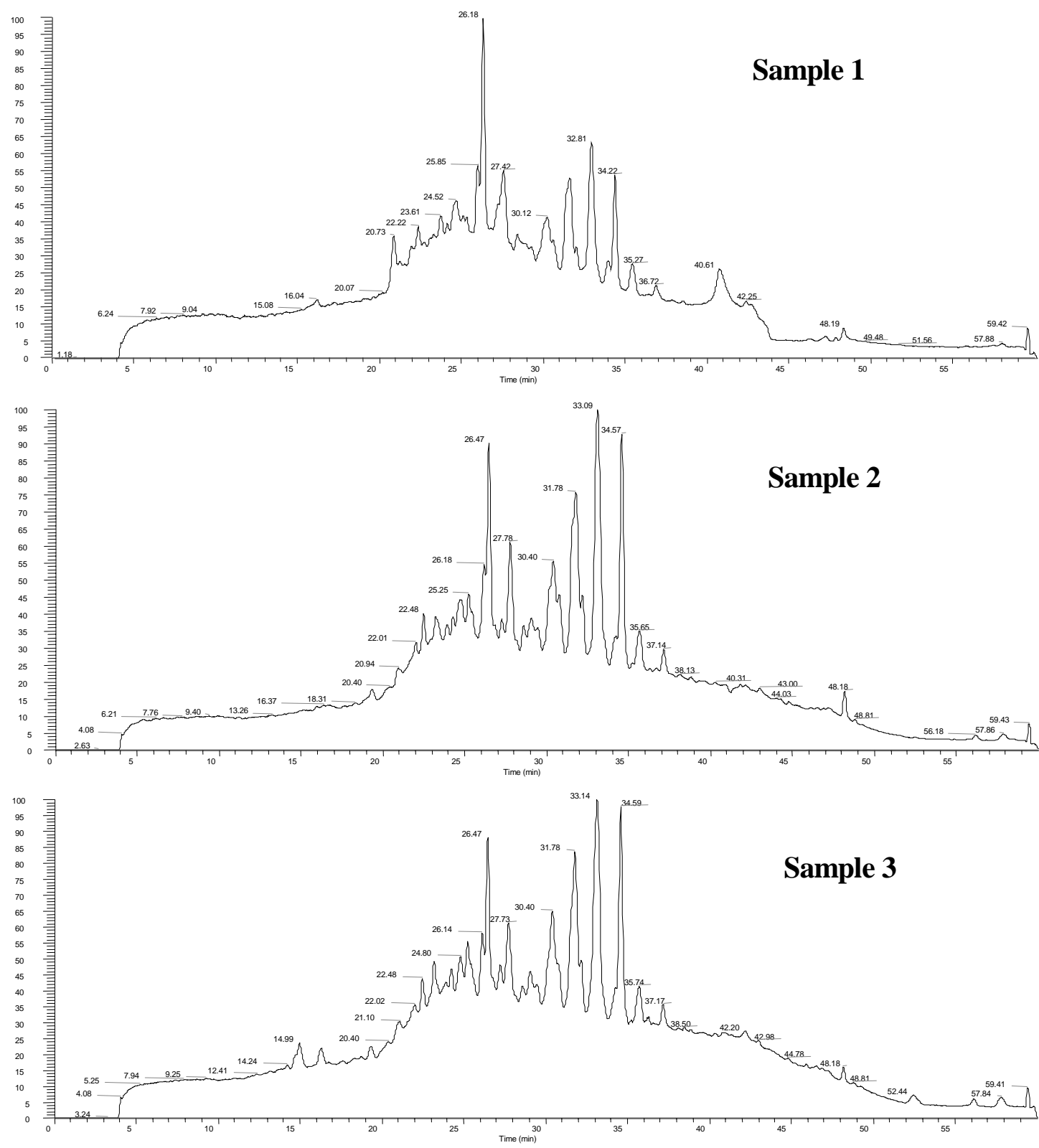

Figure 2. Total ion chromatogram for samples 1, 2 and 3 via LC-MS

without pre-derivatization. Samples of tobacco were extracted using the method which is described in the Experimental section. The resulting extract was further semi-preparatively separated via normal phase HPLC using iso-octane/ethanol as the mobile phase. Figure 2 shows the total ion chromatogram (TIC) of the enriched SE fraction for tobacco samples 1, 2 and 3 via reversed-phase LC-MS using $\mathrm{CH}_{3} \mathrm{CN}: \mathrm{H}_{2} \mathrm{O}$ containing $1 \%$ formic acid as the mobile phase. The general characteristics of the TIC traces were similar with only subtle differences in the relative amounts 
<smiles>[R]C(=O)OC1C(COC(C)=O)OC(OC2(CO)OC(CO)C(O)C2O)C(OC(C)=O)C1OC([R])=O</smiles>

Group III

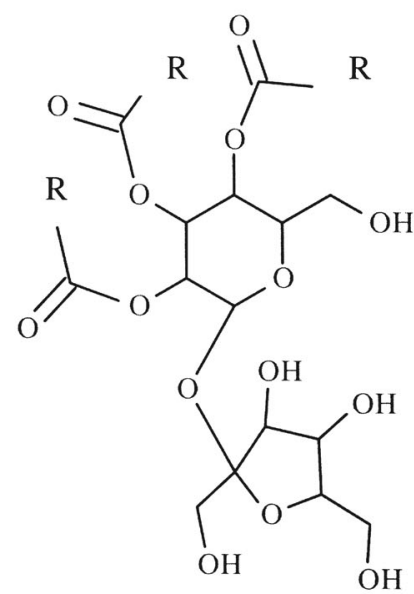

Group II<smiles>[R]C(=O)OC1C(CO)OC(OC2(CO)OC(CO)C(OC(C)=O)C2O)C(OC(C)=O)C1OC(C)=O</smiles>

Group I

Figure 3. Structure of sucrose esters $\left(R=C_{3}-C_{8}\right)$

Table 2. Anticipated molecular weight of water (or ammonium ion, $A_{+}$) adduct, parent, and ionized fragment with the acetyl group attached either to FRU (Group I) or GLU (Group III)

\begin{tabular}{l|c|c|c|c|c}
\hline $\begin{array}{l}\mathrm{H}_{2} \mathrm{O} \\
\text { (or A+) } \\
\text { adduct }\end{array}$ & Parent & $\begin{array}{c}\text { GLU+OAc } \\
\text { Fragment } \\
\text { Group III }\end{array}$ & $\begin{array}{c}\text { FRU-OAc } \\
\text { Fragment } \\
\text { Group III }\end{array}$ & $\begin{array}{c}\text { GLU-OAc } \\
\text { Fragment } \\
\text { Group I }\end{array}$ & $\begin{array}{c}\text { FRU+OAc } \\
\text { Fragment } \\
\text { Group I }\end{array}$ \\
\hline 584 & 566 & 387 & 163 & 345 & 205 \\
598 & 580 & 401 & 163 & 359 & 205 \\
612 & 594 & 415 & 163 & 373 & 205 \\
626 & 608 & 429 & 163 & 387 & 205 \\
640 & 622 & 443 & 163 & 401 & 205 \\
654 & 636 & 457 & 163 & 415 & 205 \\
668 & 650 & 471 & 163 & 429 & 205 \\
682 & 664 & 485 & 163 & 443 & 205 \\
696 & 678 & 499 & 163 & 457 & 205 \\
710 & 692 & 513 & 163 & 471 & 205 \\
724 & 706 & 527 & 163 & 485 & 205 \\
738 & 720 & 541 & 163 & 499 & 205 \\
752 & 734 & 555 & 163 & 513 & 205 \\
\hline
\end{tabular}

of the components. Samples 4 and 5 showed a similar TIC. The chromatographic and MS conditions are described in the Experimental section. As described in our previous publication (15) concerning a single tobacco sample, it was determined that SE can be divided into three groups each of which containing at least six homologs that differ by 14 amu (e.g. $\mathrm{CH}_{2}$ ). The groups can be distinguished from each other by the location of the lone acetyl ester function. Group I has the lone acetyl group attached to carbon-3 of fructose. Group II has no acetyl group on either glucose or fructose. Group III has the acetyl group attached to carbon6 of glucose, Figure 3. Table 2 shows pertinent predicted molecular weight of each major SE. They differ by $14 \mathrm{amu}$ (or one methylene) with the acetyl group attached either to glucose (GLU) or fructose (FRU). If the acetyl is attached to GLU, the corresponding fragment masses can be found under G+OAc and F-OAc and if acetyl is attached to FRU, the corresponding masses can be found under $\mathrm{G}^{-} \mathrm{OAc}$ and $\mathrm{F}+\mathrm{OAc}$.
The LC-MS data shown in Table 3 are suggestive of Group III homologs. The experimentally measured SE $m / z$ values for each parent, its water (or ammonium ion) adduct, its glucose fragment which incorporates the acetyl group, and the retention time of eluted peaks are tabulated. As can be observed, the lowest parent SE $\mathrm{m} / z$ in which acetyl is attached to GLU was detected at 566 , and the highest $\mathrm{m} / \mathrm{z}$ was found at 692. It is important to note here that no chromatographic peaks listed in Table 3 showed the presence of a $\mathrm{m} / \mathrm{z} 205$ fragment in the mass spectrum, which would have indicted acetyl attached to FRU. Surprisingly, two or three chromatographic peaks were observed for several selected ions such as 608,622 , and 636, Table 3, which suggested a certain degree of isomeric substitution. A discussion of these data follows. For sample 1, two chromatographic peaks corresponding to a water (or ammonium ion) adduct were detected for $\mathrm{m} / \mathrm{z}$ 626,640 , and 654 (Table 3). Both peaks for each $m / z$ value (626, 640 and 654) showed the presence of $m / z 429,443$, and 457 respectively, Figure 4, confirming the presence of GLU+OAc. The two peaks with water (or ammonium ion) adduct mass at 626 are believed to correspond to two $\mathrm{SE}$ that have $\mathrm{C}_{5}, \mathrm{C}_{4}$, and $\mathrm{C}_{4}$ acyl moieties on the glucose and $\mathrm{C}_{5}, \mathrm{C}_{5}$, and $\mathrm{C}_{3}$ acyl moieties on glucose. In each case, both of the chromatographic peaks for $\mathrm{m} / \mathrm{z} 640$ and 654 showed the presence of corresponding $\mathrm{m} / \mathrm{z}, 443$ and 457 fragments indicative of GLU+OAc. In the case for $m / z$ 640, one of the peaks would correspond to $\mathrm{SE}$ with a $\mathrm{C}_{6}, \mathrm{C}_{4}$, and $\mathrm{C}_{4}$ acyl and the second peak would correspond to a molecule where $\mathrm{R}$ groups are $\mathrm{C}_{5}, \mathrm{C}_{5}, \mathrm{C}_{4}$; while for the $m / z 654$, it is believed that one of the $\mathrm{SE}$ has $\mathrm{C}_{6}, \mathrm{C}_{5}$, and $\mathrm{C}_{4}$ as $\mathrm{R}$ groups, while the second peak has $\mathrm{C}_{5}, \mathrm{C}_{5}$, and $\mathrm{C}_{5}$ as $\mathrm{R}$ groups. This trend was also true for samples 2-5. It was interesting to detect three chromatographic peaks corresponding to $m / z 598$ for samples $2-5$. All three peaks in these four samples showed a fragment at 401 indicative of GLU+OAc, Figure 5. It is believed that peaks correspond to $\mathrm{SE}$ with a $\mathrm{C}_{4}, \mathrm{C}_{4}, \mathrm{C}_{3}$ and $\mathrm{C}_{5}, \mathrm{C}_{3}, \mathrm{C}_{3}$, and $\mathrm{C}_{5}, \mathrm{C}_{4}, \mathrm{C}_{2}$. Unfortunately, we were not able to identify which peak has what grouping of R. Thus, for samples 1-5, the composition of the Group III SE ranges from three ester groups having a total of 15 carbons to three ester groups having a total of 11 carbons. 
Table 3. Group III: Retention time ( $\left.t_{\mathrm{R}}, \mathrm{min}\right)$ of observed chromatographic peaks (TIC) and corresponding ion masses in five Oriental tobacco samples

\begin{tabular}{|c|c|c|c|c|c|c|c|c|c|c|c|c|c|c|c|c|c|}
\hline \multirow[b]{2}{*}{ Carbons } & \multirow{2}{*}{$\begin{array}{l}\text { Water } \\
\text { (or } A+{ }^{a} \text { ) } \\
\text { adduct }\end{array}$} & \multirow[b]{2}{*}{ Parent } & \multirow[b]{2}{*}{$\begin{array}{c}\text { GLU+OAc } \\
\text { Fragment }\end{array}$} & \multicolumn{2}{|c|}{ Sample 1} & \multicolumn{3}{|c|}{ Sample 2} & \multicolumn{3}{|c|}{ Sample 3} & \multicolumn{3}{|c|}{ Sample 4} & \multicolumn{3}{|c|}{ Sample 5} \\
\hline & & & & $\begin{array}{c}t_{\mathrm{R}} \\
\text { Pk. } 1\end{array}$ & \begin{tabular}{|c|}
$t_{\mathrm{R}}$ \\
$\mathrm{Pk} .2$
\end{tabular} & $\begin{array}{c}t_{\mathrm{R}} \\
\mathrm{Pk} .1\end{array}$ & \begin{tabular}{|c|}
$t_{\mathrm{R}}$ \\
$\mathrm{Pk} .2$
\end{tabular} & \begin{tabular}{|c|}
$t_{\mathrm{R}}$ \\
Pk. 3
\end{tabular} & $\begin{array}{c}t_{\mathrm{R}} \\
\text { Pk. } 1\end{array}$ & \begin{tabular}{|c|}
$t_{\mathrm{R}}$ \\
$\mathrm{Pk} .2$
\end{tabular} & \begin{tabular}{|c|}
$t_{\mathrm{R}}$ \\
Pk. 3
\end{tabular} & $\begin{array}{c}t_{\mathrm{R}} \\
\text { Pk. } 1\end{array}$ & \begin{tabular}{|c|}
$t_{\mathrm{R}}$ \\
Pk. 2
\end{tabular} & $\begin{array}{c}t_{\mathrm{R}} \\
\text { Pk. } 3\end{array}$ & $\begin{array}{c}t_{\mathrm{R}} \\
\mathrm{Pk} .1\end{array}$ & \begin{tabular}{|c|}
$t_{\mathrm{R}}$ \\
Pk. 2
\end{tabular} & $\begin{array}{c}t_{\mathrm{R}} \\
\text { Pk. } 3\end{array}$ \\
\hline$C_{10}$ & 584 & 566 & 387 & 25.60 & & 25.86 & & & 25.90 & & & 25.97 & & & 25.90 & & \\
\hline$C_{11}$ & 598 & 580 & 401 & 27.00 & & 24.73 & 26.86 & 27.26 & 24.73 & 26.84 & 27.26 & 24.78 & 26.89 & 27.28 & 24.78 & 26.91 & 27.33 \\
\hline $\mathrm{C}_{12}$ & 612 & 594 & 415 & 27.87 & & 28.13 & & & 28.20 & & & 28.22 & & & 28.25 & & \\
\hline $\mathrm{C}_{13}$ & 626 & 608 & 429 & 27.33 & 29.18 & 27.61 & 29.44 & & 27.57 & 29.51 & & 27.60 & 29.58 & & 27.61 & 29.56 & \\
\hline $\mathrm{C}_{14}$ & 640 & 622 & 443 & 28.78 & 30.49 & 29.06 & 30.77 & & 29.04 & 30.77 & & 29.13 & 30.82 & & 29.11 & 30.82 & \\
\hline $\mathrm{C}_{15}$ & 654 & 636 & 457 & 30.67 & 31.87 & 30.42 & 32.23 & & 30.40 & 32.20 & & 30.45 & 32.22 & & 30.47 & 32.25 & \\
\hline$C_{16}$ & 668 & 650 & 471 & 31.45 & & 31.76 & & & 31.76 & & & 31.80 & & & 31.81 & & \\
\hline$C_{17}$ & 682 & 664 & 485 & 32.80 & & 33.09 & & & 33.14 & & & 28.64 & 33.19 & & 33.14 & & \\
\hline $\mathrm{C}_{18}$ & 696 & 678 & 499 & 34.24 & & 33.56 & 34.57 & & 33.56 & 34.57 & & 33.61 & 34.62 & & 34.62 & & \\
\hline$C_{19}^{10}$ & 710 & 692 & 513 & 35.62 & & 36.02 & & & & & & 36.07 & & & 36.02 & & \\
\hline
\end{tabular}

${ }^{\mathrm{a}} \mathrm{A}+=$ ammonium ion

100 mm column

SE Sample 1
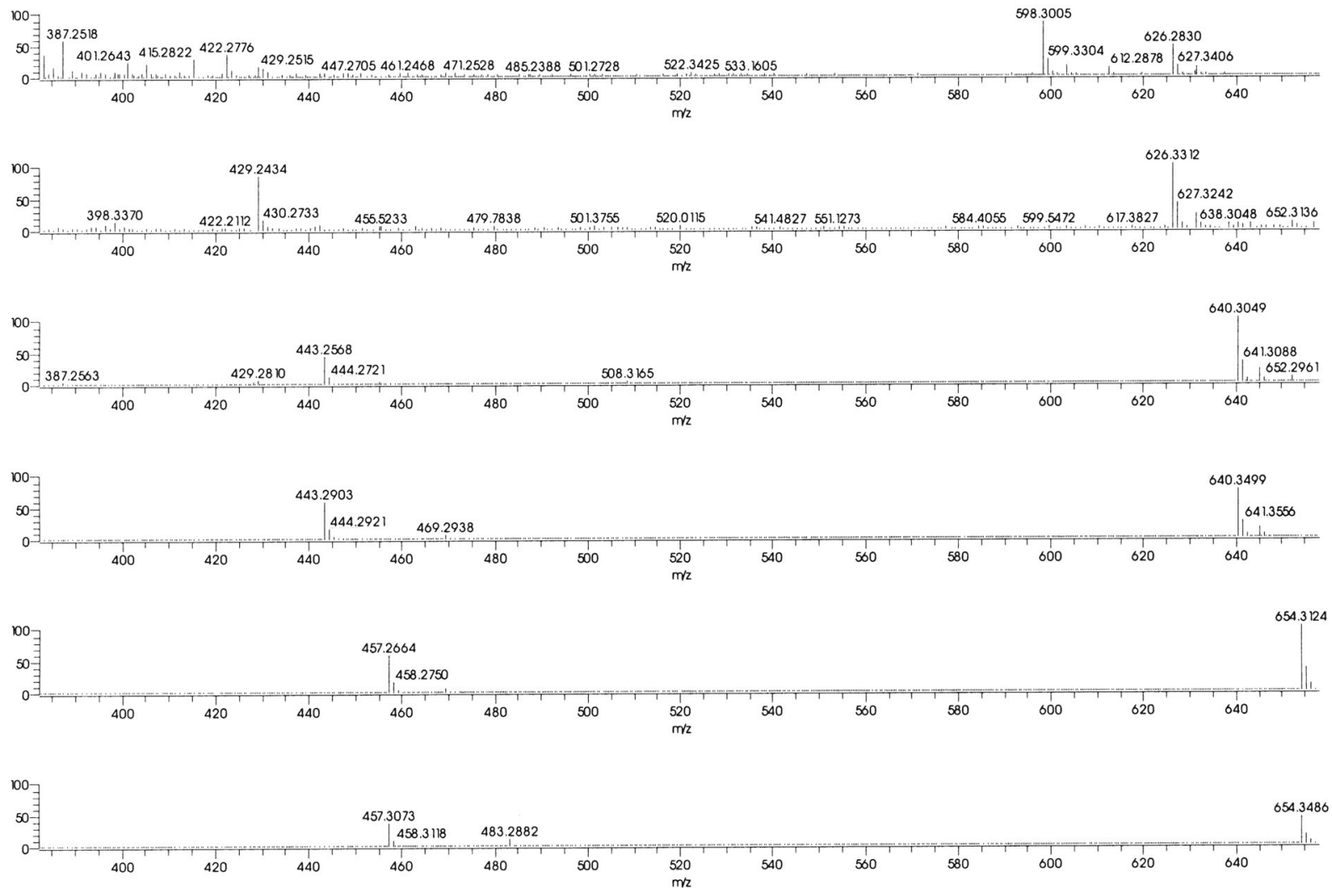

Figure 4. Mass spectra of extracted ions: $m / z 626$ (A, B), 640 (C, D), $m / z 654$ (E, F)

For samples 2-4, two peaks were also detected for $\mathrm{m} / \mathrm{z}$ 696. The mass spectrum for all peaks with $\mathrm{m} / \mathrm{z} 696$ in all three samples showed a fragment at $\mathrm{m} / \mathrm{z}$ 499. Figure 6 shows the full mass spectrum of the $\mathrm{m} / \mathrm{z} 696$ peak in sample 3. It is believed that the chromatographic peaks correspond to $\mathrm{SE}$ with $\mathrm{C}_{6}, \mathrm{C}_{6}, \mathrm{C}_{6}$ and $\mathrm{C}_{7}, \mathrm{C}_{6}, \mathrm{C}_{5}$. Again we were not able to identify which peak has what grouping of $\mathrm{R}$. Surprisingly, both samples 1 and 5 showed only one peak for $m / z$ 696. Only sample 4 showed two peaks for $m / z 682$. Both peaks showed the expected fragment at 485 . The remaining SE-water (or ammonium ion) adducts in Table 3 showed only a single chromatographic peak. Thus, to- bacco samples 1 and 5 are unique in their Group III SE composition having a single SE distribution corresponding to 18 carbons. On the other hand, samples $2-4$ have an isomeric distribution of the six carbon esters. The characteristics of the Group III SE from these Oriental tobacco samples are as follows: 1) for samples 1-5 the minimum number of ester carbons is 10 with a maximum of $19 ; 2$ ) samples 2-5 possess three isomeric SE having a total of 11 carbons, i.e. $\mathrm{C}_{5}, \mathrm{C}_{4}, \mathrm{C}_{3}$ or $\mathrm{C}_{5}, \mathrm{C}_{3}, \mathrm{C}_{3}$ or $\mathrm{C}_{5}, \mathrm{C}_{4}, \mathrm{C}_{2} ; 3$ ) samples 2-4 have two SE isomers having a total of 18 carbons, i.e. $\mathrm{C}_{6}, \mathrm{C}_{6}, \mathrm{C}_{6}$ or $\mathrm{C}_{7}, \mathrm{C}_{6}, \mathrm{C}_{5}$; 4) samples $1-5$ have only one $\mathrm{SE}$ isomer having a total of 18 carbons; 5) sample 4 has 

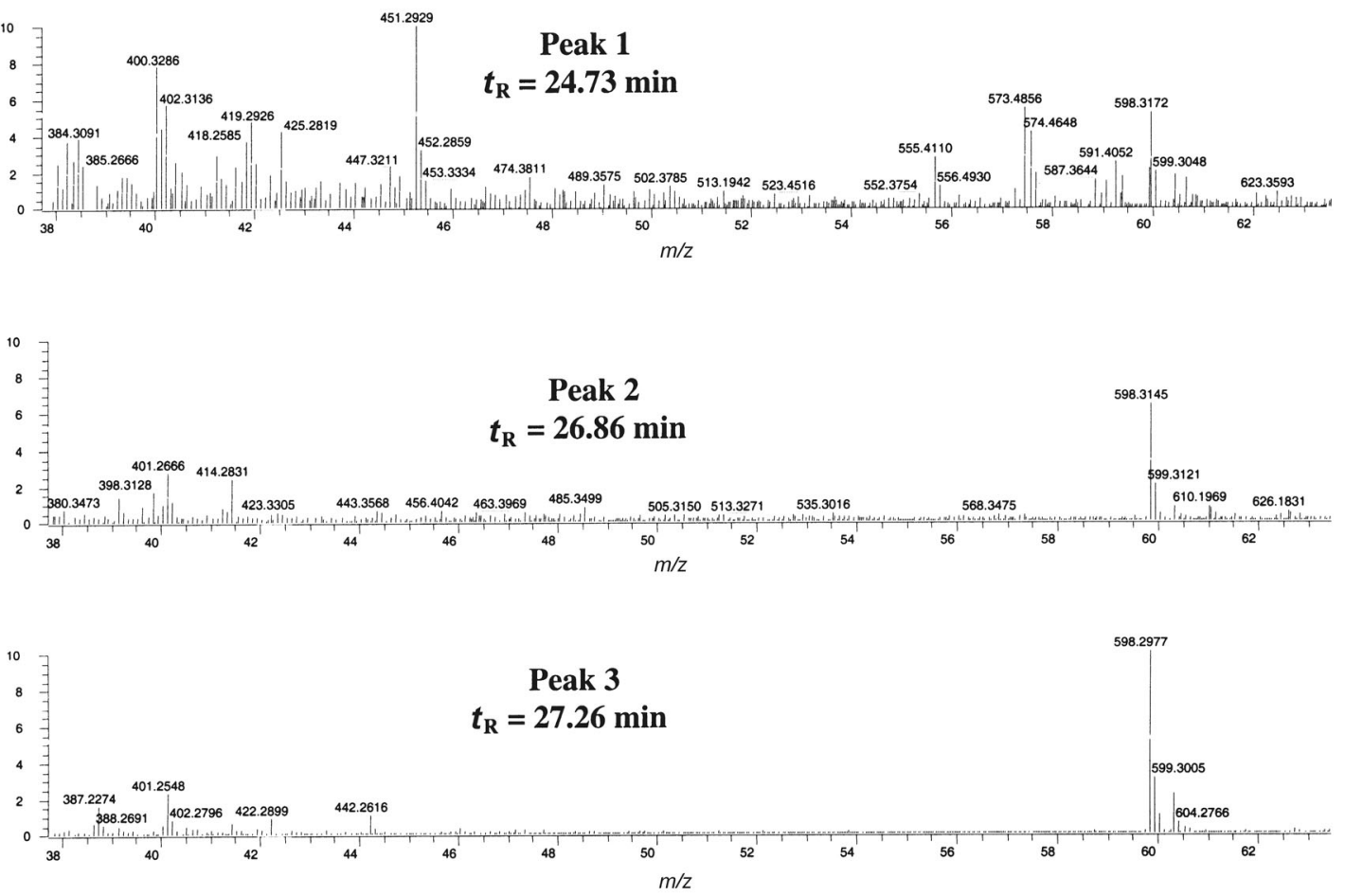

Figure 5. Mass spectra of extracted ion $m / z 598$ for sample 2
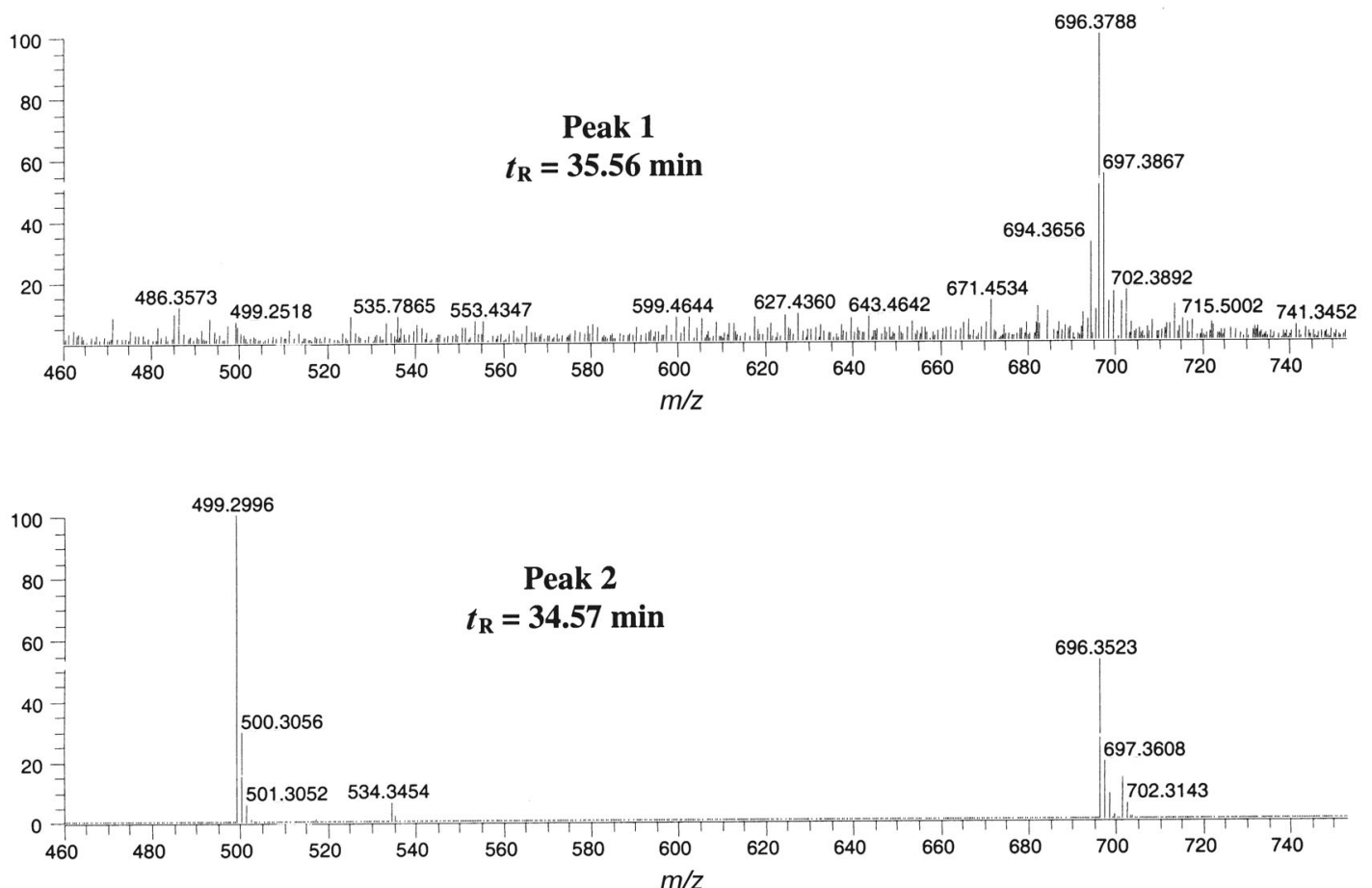

Figure 6. Spectra of extracted ion $m / z 696$ for sample 3

two SE isomers having 17 carbons, and 6) all five samples have isomer distributions with SE having a total of 13, 14, and 15 ester carbons. These results confirm a wide array of Group III components.

Table 4 shows the anticipated MW of each parent SE in group I, its water (or ammonium ion) adduct, the glucose fragment which now does not contain an acetyl, and the retention time of the single eluted peak per each parent ion.
In all these cases, the mass spectra showed $\mathrm{m} / \mathrm{z} 205$ which corresponded to FRU containing the acetyl function. The five chromatographic peaks observed for each tobacco extract correlated to $\mathrm{m} / \mathrm{z}, 682,696,710,724$, and 738 each of which can be assigned to the water (or ammonium ion) adduct of the respective SE in Group I. It is important to note here that these type adducts were only observed with SE molecules that have acyl groups on GLU equal to or 
Table 4. Group I: Retention time ( $t_{\mathrm{R}}$, $\mathrm{min}$ ) of observed chromatographic peaks (TIC) and corresponding ion masses in five Oriental tobacco samples

\begin{tabular}{l|c|c|c|c|c|c|c|c|c}
\hline Carbons & $\begin{array}{c}\text { Water }\left(\text { or } \mathrm{A}^{\mathrm{a}}{ }^{\mathrm{a}} \text { adduct }\right. \\
\text { addut }\end{array}$ & Parent & $\begin{array}{c}\text { GLU+OAc } \\
\text { Fragment }\end{array}$ & $\begin{array}{c}\text { Fru+OAc } \\
\text { Fragment }\end{array}$ & $\begin{array}{c}\text { Sample 1 } \\
t_{\mathrm{R}} \text { Peak 1 }\end{array}$ & $\begin{array}{c}\text { Sample 2 } \\
t_{\mathrm{R}} \text { Peak 1 }\end{array}$ & $\begin{array}{c}\text { Sample 3 } \\
t_{\mathrm{R}} \text { Peak 1 }\end{array}$ & $\begin{array}{c}\text { Sample 4 } \\
t_{\mathrm{R}} \text { Peak 1 }\end{array}$ & $\begin{array}{c}\text { Sample 5 } \\
t_{\mathrm{R}} \text { Peak 1 }\end{array}$ \\
\hline $\mathrm{C}_{17}$ & 682 & 664 & 443 & 205 & 31.01 & 31.34 & & & \\
$\mathrm{C}_{18}$ & 696 & 678 & 457 & 205 & 32.39 & 32.74 & 32.79 & 32.79 & 32.84 \\
$\mathrm{C}_{19}$ & 710 & 692 & 471 & 205 & 33.82 & 34.24 & 34.26 & 34.33 & 34.27 \\
$\mathrm{C}_{20}$ & 724 & 706 & 485 & 205 & 35.29 & 35.65 & 35.69 & 35.69 & 35.72 \\
$\mathrm{C}_{21}$ & 738 & 720 & 499 & 205 & 36.75 & 37.14 & 37.17 & 37.17 & 37.17 \\
\hline
\end{tabular}

${ }^{\mathrm{a}} \mathrm{A}+=$ ammonium ion.

Table 5. Observed chromatographic peaks (TIC) wherein unsaturation was assigned in five Oriental tobacco samples

\begin{tabular}{|c|c|c|c|c|c|c|c|c|c|c|c|c|c|c|c|}
\hline \multirow[b]{2}{*}{ Carbons } & \multirow{2}{*}{$\begin{array}{l}\text { Water } \\
\text { (or A+) } \\
\text { adduct }\end{array}$} & \multirow[b]{2}{*}{ Parent } & \multirow[b]{2}{*}{$\begin{array}{l}\mathrm{GLU}+\mathrm{OAC} \\
\text { Fragment }\end{array}$} & \multicolumn{2}{|c|}{ Sample 1} & \multicolumn{2}{|c|}{ Sample 2} & \multicolumn{3}{|c|}{ Sample 3} & \multicolumn{3}{|c|}{ Sample 4} & \multicolumn{2}{|c|}{ Sample 5} \\
\hline & & & & \begin{tabular}{|c|}
$t_{R}$ \\
Peak 1 \\
\end{tabular} & $\begin{array}{c}t_{\mathrm{R}} \\
\text { Peak 2 } \\
\end{array}$ & $\begin{array}{c}t_{\mathrm{R}} \\
\text { Peak1 }\end{array}$ & $\begin{array}{c}t_{\mathrm{R}} \\
\text { Peak 2 } \\
\end{array}$ & $\begin{array}{c}t_{\mathrm{R}} \\
\text { Peak 1 }\end{array}$ & $\begin{array}{c}t_{\mathrm{R}} \\
\text { Peak } 2 \\
\end{array}$ & $\begin{array}{c}t_{\mathrm{R}} \\
\text { Peak 3 } \\
\end{array}$ & $\begin{array}{c}t_{\mathrm{R}} \\
\text { Peak 1 } \\
\end{array}$ & $\begin{array}{c}t_{\mathrm{R}} \\
\text { Peak } 2\end{array}$ & \begin{tabular}{|c|}
$t_{\mathrm{R}}$ \\
Peak 3 \\
\end{tabular} & $\begin{array}{c}t_{\mathrm{R}} \\
\text { Peak 1 } \\
\end{array}$ & $\begin{array}{c}t_{\mathrm{R}} \\
\text { Peak 2 } \\
\end{array}$ \\
\hline $\mathrm{C}_{12}$ & 610 & 592 & 413 & & & & & & & & 26.89 & & & & \\
\hline $\mathrm{C}_{13}$ & 624 & 606 & 427 & 28.13 & & 27.92 & & 28.13 & & & 28.13 & & & 28.05 & \\
\hline $\mathrm{C}_{14}$ & 638 & 620 & 441 & & & & & & & & 29.35 & 29.86 & & & \\
\hline $\mathrm{C}_{15}$ & 652 & 634 & 455 & 28.99 & 29.49 & 28.99 & 31.13 & 28.99 & 29.49 & 31.15 & 29.06 & 29.53 & 31.17 & 29.09 & 29.49 \\
\hline $\mathrm{C}_{16}$ & 666 & 648 & 469 & 31.10 & 30.28 & 30.09 & 30.80 & 30.10 & 30.28 & & 30.14 & 30.84 & & 30.17 & 30.85 \\
\hline $\mathrm{C}_{17}$ & 680 & 662 & 483 & 31.55 & 32.11 & 31.55 & 32.13 & 31.55 & 32.11 & & 31.59 & 32.18 & & 31.60 & 32.16 \\
\hline $\mathrm{C}_{18}$ & 694 & 676 & 497 & 32.65 & 33.36 & 32.79 & 33.49 & & & & 32.86 & 33.51 & & 33.52 & \\
\hline
\end{tabular}

larger than $\mathrm{C}_{5}$. Samples 3-5 did not showed any peak for $m / z$ 682. The other $m / z$ peaks were present in all five samples. Somewhat surprisingly no isomerism was however noted in these Group I SE as was found for the Group III SE, vide supra. The characteristics of the Group I SE from these Oriental tobacco samples are as follows: 1) for samples 1-5 the minimum number of ester carbons was 17 with a maximum of $21 ; 2$ ) the SE with 17 carbons was only found in samples 1 and 2;3) no isomerization was noted for the Group I SE in contrast to that found for the Group III SE; 4) the average molecular weight for the Group I SE was higher than the Group III SE; 5) the range of molecular weights was more narrow for the Group I SE vs. the Group III SE.

Table 5 shows the molecular weight of parent unsaturated SE, its water (or ammonium ion) adduct, and the GLU fragment which contains the acetyl group. It is believed this sub-group is similar to Group III where acetyl is also attached to GLU. The primary difference in this sub-group is that the acyl groups attached to GLU are unsaturated. Our results, however, suggest that only one of the acyl groups has a double bond. It is interesting to observe that most $\mathrm{m} / \mathrm{z}$ values yield multiple chromatographic peaks, Table 4. Samples 1-3 and 5 did not show any peaks for $\mathrm{m} / \mathrm{z} 610$ and 638; while sample 4 showed one peak for $\mathrm{m} / \mathrm{z}$ 610 and two peaks for $m / z$ 639. Also, it was interesting to detect 3 peaks at $m / z, 652$ for samples 3 and 4. Sample 3 did not show the presence of $\mathrm{m} / \mathrm{z}$ 694. No attempt was made to determine the position of the double bond. It is important to note here that the loss of $\mathrm{m} / \mathrm{z} 197$ which is water adduct of FRU was observed for all the spectra in this series of peaks. The characteristics of the SE with unsaturated groups attached are as follows: 1) the molecular weight profile is like unto that observed for the Group
III SE; 2) for samples 1-5 the minimum number of ester carbons was 12 with a maximum of $18 ; 3$ ) only sample 4 had a SE with a total of 12 and 14 carbons; 4) all samples had SE with 13 carbons; 5) isomers for these SE with 15, 16 , and 17 carbons were observed for all samples; 6) sample 3 had no SE with a total or 13 carbons.

\section{SUMMARY AND CONCLUSIONS}

Sucrose esters from five different tobaccos were extracted and first quantitatively analyzed via GC-MS as the trimethylsilane (TMS) derivatives and secondly analyzed molecularly via LC-MS as the hydroxylated parent. Concentrations of SE in the various tobaccos differed when GC-MS was used as a tool for the quantification. It appeared that in the five tobaccos, the five chosen SE-derived molecular masses increased in the order $m / z 622<636<$ $678<650<664$ for samples $1-3$, but for samples 4 and 5 , $\mathrm{m} / \mathrm{z} 678$ and 650 were reversed. The $\mathrm{m} / \mathrm{z}$ of 664 corresponds to a group of esters having 17 carbons most likely distributed as $\mathrm{C}_{6}, \mathrm{C}_{6}$, and $\mathrm{C}_{5}$ esters. The tobacco samples consisted of a relatively large range of $\mathrm{SE}$ concentrations. It was determined that sample 2 contained the highest concentration $(950 \mu \mathrm{g} / \mathrm{g})$ and sample 3 contained the lowest concentration $(340 \mu \mathrm{g} / \mathrm{g})$ of SE. When LC-MS was used for qualitative analysis, the lowest parent $\mathrm{SE} \mathrm{m} / \mathrm{z}$ in which acetyl was attached to GLU was detected at $m / z, 566$ (10 carbons), and the highest $\mathrm{m} / \mathrm{z}$ was found at 692 (19 carbons). None of these analytes showed the presence of acetyl attached to FRU $(m / z, 205)$. Some $m / z$ showed more than one peak which indicated the presence of isomers. All samples showed the presence of SE wherein acetyl was attached to FRU (i.e. $\mathrm{m} / \mathrm{z}$ 205). Each sample showed the 
presence of at least 5 peaks. Also acyl unsaturation was observed, where only the GLU fragment contained the acetyl groups. It is believed this sub-group is similar to Group III where acetyl is also attached to GLU. The primary difference in this sub-group is that one of the acyl groups attached to GLU are unsaturated. The quantitative results on ester group distribution are in general agreement with those of SEVERSON (10) and EINOLF (18). However, from a qualitative perspective more detailed information on isomer distribution for Oriental tobacco SE has been presented. Also, the first detailed description of ester groups in SE having unsaturation has been reported.

\section{REFERENCES}

1. Cutler, H.G., R.F. Severson, and P.D. Cole: The biological activity of some mixed sucrose and glucose esters from exotic tobacco cultivars; PGRSA Quarterly 20, 1992, pp. 18-28.

2. Steffens, J.C. and D.S. Walters: Biochemical aspects of glandular trichome-mediated insect resistance in the Solanaceae; in: Naturally occurring pest bioregulators, edited by P.A. Hedin, ACS, Washington, DC, 1991, pp. 136-149.

3. Schumacher, J.N.: The isolation of 6-O-acetyl-2,3,4tri-O-((+)-3-methylvaleryl)-beta-D-glucopyranose from tobacco; Carbohydr. Res. 13 (1970) 1-8.

4. Leffingwell, J.C. and D. Leffingwell: Chemical and sensory aspects of tobacco flavor; Rec. Adv. Tob. Sci. 14 (1988) 169-218.

5. Lin, Y. and G.J. Wagner: Rapid and simple method for estimation of sugar esters; J. Agric. Food Chem. 42 (1994) 1709-1712.

6. Matsuzaki, T., Y. Shinozaki, and S. Suhara: Isolation and characterization of tetra-and triacylglucose from surface lipids of N. miersii; Agric. Biol. Chem. 53 (1989) 3343-3345.

7. Severson, R.F., R.F. Arrendale, O.T. Chortyk, A.W. Johnson, D.M. Jackson, G.R. Gwynn, J.F. Chaplin, and M.G. Stephenson: Quantitation of the major cuticular components from green leaf of different tobacco types; J. Agric. Food Chem. 32 (1984) 566-570.

8. Arrendale, R.F., R.F. Severson, and V.A. Sisson: Characterization of the sucrose ester fraction from Nicotiana glutinosa; J. Agric. Food Chem. 38 (1990) 75-85.

9. Severson, R.F., R.F. Arrendale, and O.T. Chortyk: Isolation and characterization of sucrose esters of the cuticular waxes of green tobacco leaf; J. Agric. Food Chem. 33 (1985) 870-875.
10. Severson, R.F., A.W. Johnson, and D.M. Jackson: Cuticular constitutents of tobacco: factors affecting their production and their role in insect and disease resistance and smoke quality; Rec. Adv. Tob. Sci. 11 (1985) 105-173.

11. Severson, R.F., R.F. Arrendale, O.T. Chortyk, C.R. Green, F.A. Thomas, J.L. Stewart, and A.W. Johnson: Isolation and characterization of sucrose esters of the cuticular waxes of green tobacco leaf; J. Agric. Food Chem. 33 (1985) 780-875.

12. Danehower, D.A.: A rapid method for the isolation and quantification of the sucrose esters of tobacco; Tob. Int. 189 (1987) 30-33.

13. Kandra, L. and G.J. Wagner: Studies of the site and mode of biosynthesis of tobacco trichome exudates component; Archives Biochem. Biophys. 265 (1988) 425-432.

14. Ashraf-Khorassani, M., N. Nazem, L.T. Taylor, and W.M. Coleman III: Isolation of tetra-acyl sucrose esters from Turkish tobacco using supercritical fluid $\mathrm{CO}_{2}$ and comparison with conventional solvent extraction; J. Agric. Food Chem. 53 (2005) 1866-1872.

15. Ashraf-Khorassani, M., N. Nazem, L.T. Taylor, and W.M. Coleman III: Separation and identification of sucrose esters from Turkish tobacco using liquid chromatography-mass spectrometry; Beitr. Tabakforsch. Int. 21 (2005) 380-389.

16. Wagner, G.: Leaf surface chemistry; in: Tobacco: Production, Chemistry, and Technology, edited by D.L. Davis and M.T. Nielsen, Blackwell Science LTD., London, 1999, pp. 292-303.

17. Leffingwell, J.C.: Basic chemical constituents of tobacco leaf and differences among tobacco types; in: Tobacco: Production Chemistry, and Technology, edited by D.L. Davis and M.T. Nielsen, Blackwell Science LTD, London, 1999, pp. 265-284.

18. Einolf, W.N. and W.E. Chan: Estimation of sucrose esters in tobacco by direct chemical ionization mass spectrometry; J. Agric. Food Chem. 32 (1984) 785-789.

\section{Corresponding author:}

Larry Taylor

Department of Chemistry

Virginia Tech

Blacksburg, VA 24061-0212

USA

E-mail:ltaylor@vt.edu 